\title{
MODERNOS DESAFIOS À GESTÃo DO APARELHO PRODUTIVO
}

\author{
João Manuel Vilas-Boas da Silva
}

\section{INTRODUÇÃO}

Na primeira secção deste artigo irá analisar-se o quadro de referências no qual se enquadram presentemente as organizações industriais. Salientar-se-á, em particular, o papel que o sistema de fabrico pode ter na criação da vantagem competitiva.

De seguida vai estabelecer-se o âmbito da função Gestão da Produção. Irão analisar-se as mais importantes vertentes desta função no seio da organização, de modo a poder imprimir a dinâmica necessária ao sistema de fabrico para que este desempenhe o papel estabelecido.

$\mathrm{Na}$ última secção do artigo irá focar-se um modo de implementar a mudança na empresa industrial. De facto, a organização necessita de mudar para acompanhar ou mesmo para se antecipar à evolução do contexto, criando assim uma vantagem competitiva sobre a concorrência.

\subsection{As Raízes da Indústria do Pós-Guerra}

Nas últimas décadas, o contexto competitivo da indústria tem vindo a sofrer uma sucessão de profundas alterações na sua caracterização.

Assim, rapidamente se transformou o cenário emergente da $2 .{ }^{a}$ Grande Guerra, conotado com a escassez da oferta, a produção em massa e a orientação para o produto. Os senhores da indústria de então, os EUA e o Reino Unido, usufruíram de um período de monopólio, garantido pela completa destruição da indústria dos restantes países, nomeadamente a Alemanha, a França, o Japão e a Itália.

Este monopólio manifestou-se, por exemplo, na indústria automóvel Britânica que na década de 50 vendia todos os carros que conseguia fabricar, exportando $80 \%$ da sua produção e constituindo-se como o maior exportador mundial de automóveis. Atravessava-se então um período em que os recursos eram abundantes e baratos, estando a eficiência da sua utilização e gestão relegadas para segundo plano. 
Progressivamente a situação vai-se invertendo, até que na década de 70 a oferta ultrapassa a procura, assistindo-se então a um predomínio das preocupações de carácter financeiro e comercial em detrimento da produção. Muitas empresas orientavam-se para o mercado e a estratégia empresarial dominante favorecia a introdução de novos produtos, a diferenciação e a redução de custos. É nesta altura que se acentua a perda de «status» da função produção no Ocidente. Apesar de numa empresa industrial 70-80\% dos activos, despesas e pessoal pertencerem à fábrica, os seus gestores passam a ser afastados dos centros de tomada de decisão. Esta realidade levou a que muitas decisões de investimento e de estratégia empresarial, por exemplo, fossem desadequadas. Por outro lado, e por oposição, no Japão e na Alemanha era pré-requisito do Administrador o conhecimento e entendimento profundos do sistema de fabrico. Este era, nestes países, reconhecido e tratado em toda a sua plenitude e importância como o «motor» da empresa industrial.

No Ocidente, a função Produção era então considerada, para muitos executivos, como um «mal necessário»: empatava capital em instalações e stocks, resistia à mudança dos produtos e mercados, a qualidade dos seus produtos e serviços nunca era tão boa quanto deveria, os seus colaboradores não eram suficientemente sofisticados, eram maçadores e orientados para detalhes técnicos que só eles entendiam.

Esta atitude de marginalização levou a que a Produção se tornasse uma função orientada para si própria, focada exclusivamente na fábrica, reactiva, preocupada com o curto prazo e com questões meramente técnicas.

De facto, nos anos 70 muitas das empresas industriais ocidentais eram ainda geridas segundo os critérios primitivos de eficiência e produtividade, baseados na teoria da organização científica do trabalho, os quais se tinham revelado eficazes nos anos 40 e 50.

\subsection{A Evolução do Contexto Envolvente das Organizações Industriais}

\subsubsection{Aspectos Competitivos}

A crescente consciencialização dos consumidores tem vindo a implicar uma subida dos seus padrões de exigência, suportados pelas maiores possibilidades de escolha oferecidas pelo mercado. Estas exigências traduzem-se em expectativas de maior qualidade, conformidade com os requisitos, sofisticação e mesmo personalização dos produtos.

O impacto deste comportamento dos consumidores nos fabricantes traduz-se basicamente em necessidades de fabrico de uma maior variedade de melhores e mais baratos produtos e no fornecimento de melhores serviços. 
Por outro lado, as empresas deparam ainda com dificuldades acrescidas, devidas à globalização do mercado e ao encurtamento dos ciclos de vida dos produtos.

A globalização do mercado permite que empresas de diferentes países venham a competir nos mais diversos mercados em igualdade de circunstâncias, devido à queda das barreiras alfandegárias e legais e a acordos bi e multi-laterais. A consequência mais evidente é que deixam de estar no mercado doméstico ou no internacional e passam simplesmente a concorrer num mercado global. O segundo aspecto da globalização diz respeito à possibilidade das empresas implantarem as suas unidades industriais nos países onde lhes for mais vantajoso, o que poderá também eliminar custos de transporte e distribuição, para além das barreiras legais e psicológicas.

Uma estratégia possível de liderança de mercado passa pela frequente introdução de alterações nos produtos, de modo a evitar o plágio da concorrência. Ora, isto diminui consideravelmente o ciclo de vida dos produtos, obrigando a um esforço de sincronização entre o Projecto e a Produção, para além de uma considerável adaptação do sistema de fabrico às novas exigências.

\subsubsection{Aspectos Tecnológicos}

As mudanças no contexto competitivo requerem e são acompanhadas por evoluções tecnológicas. Estas por sua vez permitem alterações nas formas de estar, actuar e pensar das organizações. As mais relevantes mudanças referem-se a:

- tecnologias de projecto do tipo CAD/CAM (Computer Aided Design/Computer Aided Manufacturing) que permitem reduções significativas nos tempos de desenvolvimento dos produtos e, consequentemente, nos ciclos de fabrico e prazos de entrega. Permitem ainda um aumento da produtividade através da eliminação da duplicação de esforços, da redução de erros e da integração do fabrico com o projecto;

- tecnologias de produção que deverão permitir que os equipamentos sejam integrados através de redes de comunicações e programáveis numericamente, a fim de poderem receber comandos por cabo e de poderem garantir elevados índices de repetibilidade e fiabilidade. Os equipamentos deverão ainda ser flexíveis, a fim de permitirem uma maior integração das operações de fabrico com os correspondentes aumentos de produtividade.

\subsection{A Evolução das Preocupações da Produção}

Nas décadas de 40, 50 e 60 era colocada uma forte ênfase na maximização do volume de produção. Para além disto, a estratégia produtiva baseava-se numa 
redução de custos, conseguida através de poupanças nas compras e do aumento das taxas de utilização de equipamentos e mão-de-obra.

A maximização da eficiência levou a uma maximização da divisão de tarefas e ao esvaziamento de conteúdo intelectual das funções. Devido a esta atitude e à migração da força de trabalho para o sector terciário, nos anos 70 a indústria debate-se com uma dificuldade crescente em encontrar colaboradores, para além de apresentar uma tendência crescente nos índices de absentismo e de rotação de trabalhadores. Data desta altura o aparecimento de uma preocupação dominante com os recursos humanos e com a atractividade das funções e instalações fabris.

Por outro lado, também se alteram os critérios de medição do desempenho produtivo que passam assim a divergir de alguns dos critérios financeiros tradicionais. Os stocks deixam de ser vistos como um activo, decai a importância das taxas de utilização das máquinas e homens e passa-se a considerar com crescente importância o fluir dos produtos ao longo da fábrica, no sentido, quer da diminuição do ciclo de fabrico e do em-curso-de-fabrico, quer do fabrico do produto necessário para venda. A aceitação destes novos princípios é uma das mais difíceis barreiras que os Gestores têm que ultrapassar, dado que alguns deles contrariam o saber instituído.

\subsection{Contribuição do Sistema de Fabrico para o Sucesso do Negócio}

Têm-se vindo a detectar diferentes atitudes para com o sistema produtivo das organizações, as quais se resumem de seguida:

- «mal desnecessário» - a empresa detém apenas as funções comercial e de projecto, subcontratando as funções de produção;

- «mal necessário» - a empresa mantém-se fabricante devido a uma inércia histórica, social ou política, ou porque não consegue subcontratar quem lhe fabrique os produtos nas condições requeridas;

- «eu também!» - a empresa assume que, se deve ser fabricante, então terá que ser tão eficiente quanto a concorrência;

- «melhor que os outros» - a empresa quer ser o melhor fabricante no mercado;

- «vantagem competitiva» - o sistema de fabrico é visto como o motor do negócio e como uma arma contra a concorrência. 
De todas as alternativas só há duas possibilidades. Ou se assume e se reconhece a necessidade do sistema de fabrico e então este deverá constituir-se como uma vantagem competitiva, ou não, e então subcontrata-se, eliminando-se o mal pela raiz.

A vantagem competitiva estratégica conferida pelo sistema de fabrico pode ser criada dos seguintes modos:

- através do desenvolvimento de uma reconhecida aptidão para fabricar determinados produtos;

- através da garantia de conformidade dos produtos face aos requisitos;

- através da incorporação durante o fabrico das características de funcionamento previstas no projecto;

- através de uma redução constante de custos que garanta um aumento das margens disponíveis para distribuição, reinvestimento ou redução de preços com vista ao aumento da quota de mercado;

- através da diminuição do tempo que medeia entre a expressão da necessidade do cliente e a sua satisfação pelo produto, incluindo ou não o desenvolvimento de um novo produto;

- através do fornecimento atempado da quantidade de produto requerida.

Enquanto que no passado alguns destes factores eram mutuamente exclusivos, hoje em dia as empresas industriais têm que melhorar simultaneamente áreas aparentemente incompatíveis. Por exemplo, «depressa versus bem e bom» e «custos versus qualidade e performance» não podem mais ser encarados como aspectos alternativos.

Conclui-se então que os Gestores da Produção têm que ser treinados para encarar a sua função como suporte de grande parte da vantagem competitiva estratégica do negócio de base industrial. Por outro lado, eles têm, por direito próprio, que participar nos vários níveis de decisão da organização, contribuindo para o seu sucesso como um todo.

\subsection{Os Desafios da Mudança}

A evolução do contexto de enquadramento das organizações constitui uma séria ameaça à sobrevivência das instituições que persistirem na manutenção de atitudes e estruturas que resultaram no passado, enquanto enquadradas em cenários actualmente ultrapassados. Em alternativa, esta evolução coloca um desafio e um apelo à mudança da missão, das estratégias, das estruturas, dos sistemas, das 
capacidades técnicas e dos estilos de gestão das organizações que pretendam afirmar-se no futuro.

A mudança requer pois um verdadeiro espírito empresarial aberto ao investimento e ao risco e sensível aos cenários e oportunidades emergentes.

A moderna Gestão da Produção deverá também enquadrar-se neste contexto, aceitando o desafio do novo e da competitividade conforme visto. Poderão então enumerar-se alguns dos aspectos que devem estar presentes no desempenho do «novo» Gestor da Produção:

- aceitação da mudança nas suas várias vertentes; por um lado, a inovação em que se promovem saltos qualitativos importantes e, por outro, o melhoramento contínuo que assegura a manutenção da vantagem competitiva alcançada sobre a concorrência através da inovação;

- envolvimento crescente com a tecnologia do processo de fabrico e com a sua personalização face às necessidades particulares da fábrica; mesmo que haja especialistas a conduzir este processo, ele deverá ser liderado pelo «detentor dos problemás» que é o responsável pela fábrica;

- envolvimento com a gestão estratégica do negócio e consciencialização para a organização como um todo; a fábrica somente poderá contribuir para a missão e alcance dos objectivos do negócio estando motivada para o conjunto, através de uma perspectiva sistémica de actuação;

- manutenção de um perfil profíssional actualizado, continuamente formado e treinado nas mais recentes formas de gestão do sistema produtivo.

\section{A FUNÇÃO GESTÃO DA PRODUÇÃO}

O âmbito de actuação do gestor da produção tem-se vindo progressivamente a alargar. Nesta secção irão analisar-se as suas mais importantes tarefas. Tentará também desmistificar-se a máxima de que o Gestor da Produção só se preocupa com a quantidade produzida.

\subsection{Gestão de Operações}

Uma das mais prementes necessidades do Gestor da Produção diz respeito à garantia da satisfação da procura no curto prazo. De facto, uma empresa industrial 
não poderá ser viável a menos que a «mix» de produtos requeridos seja produzida regularmente, atempadamente, nas quantidades pedidas, com a qualidade devida e satisfazendo determinados critérios de performance. Nestas condições atinge-se a conformidade com a especificação.

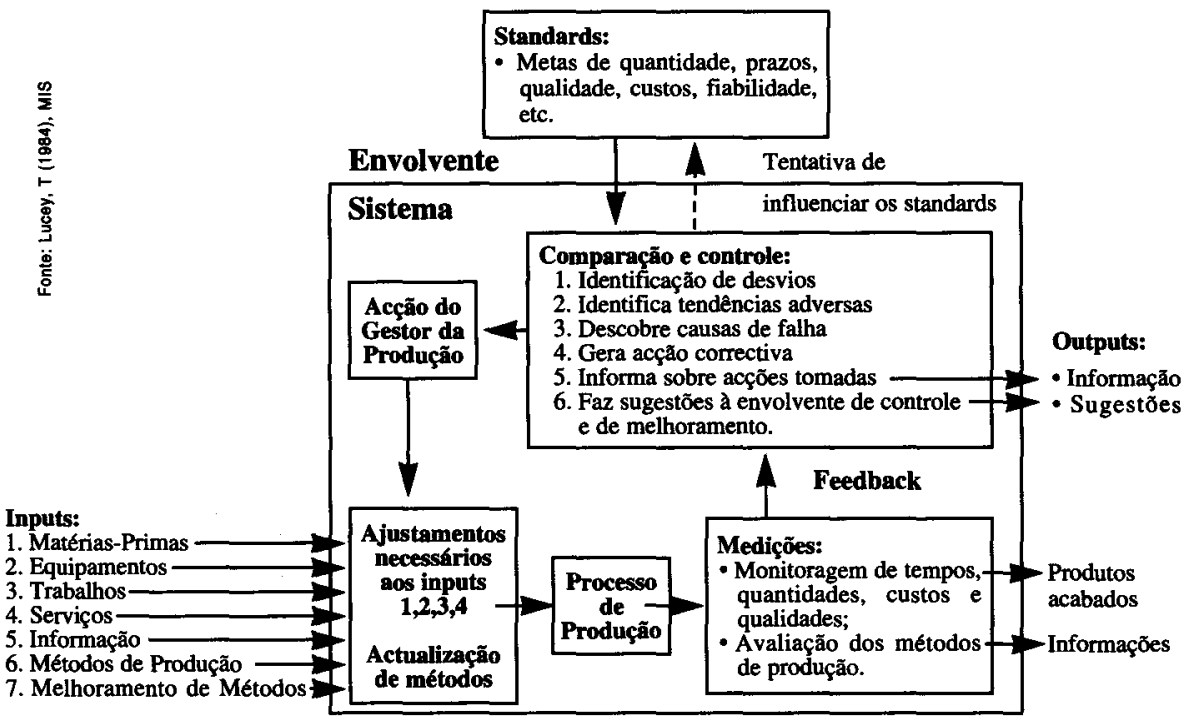

Fig. $1-$ «Input $\rightarrow$ Transformação $\rightarrow$ «Output»

A transformação física dos recursos de fabrico consumíveis (nomeadamente as matérias-primas, os componentes, a energia), pelos recursos de fabrico permanentes (nomeadamente as instalações fabris, os equipamentos e as pessoas), origina os produtos finais requeridos, desperdícios e defeituosos.

\subsection{Sistemas de Controle}

A fim de se assegurar a conformidade há que garantir que o «output» esteja de acordo com as necessidades em termos da especificação do projecto do produto, quantidade, qualidade e «timing». Para isso o Gestor da Produção deverá desenvolver e/ou utilizar variados sistemas de controle: controle da produção/materiais, controle de qualidade, controle de manutenção, controle de pessoal e controle de custos. 
A questão da conformidade complica-se, contudo, devido a vários factores:

- os objectivos planeados para o «output» não são constantes, variando devido a mudanças inesperadas da procura;

- os objectivos para o «output» são pluridimensionais, entrando por vezes em conflito: por exemplo, na tentativa de maximização da utilização dos recursos, os objectivos quantidade, «timing» e qualidade poderão interferir uns com os outros;

- o nível de conformidade depende do estado de manutenção dos equipamentos e do treino e formação dos homens.

\subsubsection{Controle da Produção}

Muitas vezes assim denominada, esta função é, de facto, constituída por duas actividades distintas: o planeamento e o controle.

\section{Planeamento}

Esta é a função da gestão em que se tenta programar antecipadamente a utilização dos recursos de produção e a sequência das operações de processamento, a fim de se produzirem os produtos requeridos no prazo exigido $\mathrm{e}$ ao custo óptimo.

A localização desta função no organograma funcional depende muito da cultura e dimensão da empresa. Quando o gestor da produção não for o seu responsável, deverá, contudo, prestar-lhe uma estreita colaboração e, por outro lado, usar na sua actividade os resultados e informação expressos nos relatórios emitidos, quer em suporte papel, quer «on line».

As principais subactividades do planeamento passam pela elaboração do programa de produção, carregamento de recursos, sequenciamento de operações, preparação de documentos de trabalho e planeamento de stocks.

De seguida, vai analisar-se o planeamento nas suas várias vertentes temporais.

\section{- Planeamento de Médio Prazo}

Embora no projecto detalhado de sistemas de planeamento haja um certo índice de subjectividade derivado da cultura da empresa e do tipo de sistema de fabrico utilizado, há contudo alguma informação estável que deve sempre constar, independentemente destas considerações. $O$ programa de produção deverá mencionar os produtos finais individualizados que se deverão produzir ao longo do período de planeamento estabelecido. Este, por sua 
vez, deverá ser repartido em subperíodos - o mês, a quinzena ou a semana. O programa de produção deverá ainda informar sobre o estado de carga previsto para todos os Centros de Trabalho, tendo em atenção as necessidades de capacidade para se produzirem os produtos intermédios necessários.

Estabelecida a capacidade requerida em horas-homem, horas-máquina ou horas-homem-máquina, estas deverão ser convertidas em unidades monetárias. $O$ programa de produção declara ainda as necessidades em materiais no período, cálculos de desperdícios e os respectivos custos. Acrescentando os restantes custos que se prevê venham a incorrer no período de planeamento, facilmente se podem gerar os orçamentos sectoriais para o nível de funcionamento previsto para a fábrica. Posto isto, é pois fácil de imaginar a importância da colaboração e/ou liderança do Gestor da Produção neste processo.

A participação do Gestor da Produção também é essencial na elaboração do programa de vendas, o qual resulta da aplicação das restrições de capacidade às previsões de vendas, determinando a «mix» de produtos a vender e o nível de actividade da empresa. É o programa de vendas que dá origem ao de produção, diferindo deste, pois normalmente considera grupos ou famílias de produtos em vez de produtos individualizados. Por outro lado, existe também um «gap» entre os períodos de vendas e de produção, isto é, um produto vendido no período 4 poderá ser fabricado no período 2 ou 3 . O programa de vendas deverá incluir o montante das receitas estimadas por período. Com estes elementos financeiros e os de custos enunciados no parágrafo anterior é possível calcular diversos indicadores financeiros previsionais, nomeadamente, o lucro e o retorno do investimento.

\section{- Planeamento de Curto Prazo}

O planeamento imediato engloba a preparação dos programas de trabalho quotidianos, ou seja, o sequenciamento da carga de trabalho conhecida e as requisições aos armazéns de materiais e ferramentas entre outros. Este tipo de trabalho está continuamente a ser revisto, daí as dificuldades que experimentam os módulos de sequenciamento das aplicações informáticas.

\section{- Planeamento de Longo Prazo}

O Gestor da Produção deve ainda participar no planeamento de longo prazo ou estratégico (5-10 anos, por exemplo), na vertente respeitante aos investimentos de expansão ou substituição dos recursos produtivos. É absolutamente imprescindível que não se façam investimentos desadequados, os quais poderiam inclusive ameaçar ou condicionar a sobrevivência do negócio. 
O Gestor da Produção também deverá integrar a comissão responsável pela fixação dos objectivos de primeira linha para o negócio. Embora outros exemplos se pudessem citar, estes parecem ser suficientemente relevantes.

\section{Controle}

Se o plano serve para iniciar a acção e funciona como um padrão face ao qual se pode avaliar o estado de avanço ou atraso, o controle é a actividade que se preocupa com a medida e análise dos desvios e a sua correcção sistemática.

Há então que preparar relatórios e compilar estatísticas que permitam suportar esta actividade.

Evidentemente que a responsabilidade para a tomada de acções correctivas recai sobre a gestão da produção, única entidade com poder executivo na fábrica, independentemente dos relatórios e/ou sugestões de correcção serem ou não da sua autoria.

Pode-se dividir a actividade de controle em duas. Uma, o progresso que se preocupa com o seguimento dos trabalhos-em-curso, evitando que estes se atrasem face à sequência estabelecida. Outra, o controle global que compila e agrega todos os elementos facultados pelo progresso, construindo, por exemplo, índices sobre o número de encomendas atrasadas num dado período e os respectivos tempos médios de atraso.

\subsubsection{Controle de Qualidade}

Basicamente a responsabilidade do Gestor da Produção para com esta função traduz-se na garantia de que a qualidade é «embutida» no produto ao longo do processo de fabrico, evitando-se assim as indesejáveis reparações e assegurando a conformidade da funcionalidade do produto face ao projecto. Para isto é necessário:

- garantir a motivação dos seus homens para o «fazer bem à primeira», para o autocontrole e para uma postura responsável;

- garantir um estado físico dos equipamentos que permita o seu bom funcionamento e o controle estatístico do processo de modo a que se elimine o fabrico do defeituoso;

- garantir que os percursos seguidos pelos produtos na fábrica sejam os que garantem as condições de produção adequadas;

- garantir a imediata suspensão de toda a actividade de fabrico que funcione deficientemente e a respectiva resolução dos problemas; 
- garantir a informação de retorno apropriada para outros departamentos, com vista à resolução de problemas; nomeadamente, «feedback» que permita modificar o projecto de produtos e equipamentos, de modo a eliminar causas de ruído;

- garantir o registo de toda a informação necessária a um rastreio eficiente da «qualidade»;

- garantir toda a colaboração necessária ao departamento de qualidade.

\subsubsection{Controle de Materiais}

Nos anos 50 as diversas famílias de materiais, desde as matérias-primas aos materiais de manutenção, passando pelos produtos intermédios e acabados eram geralmente geridos pelos chamados métodos de reaprovisionamento do tipo ponto de encomenda. Estes métodos respondiam à questão quando encomendar, baseando-se na ultrapassagem de um dado valor crítico do material em stock, existindo um stock de segurança para fazer face a desvios de procura e prazo de entrega. À questão quanto encomendar respondia a chamada quantidade económica de encomenda. Escusado será dizer que esta era uma solução bastante cómoda para os Gestores da Produção, orientada para o produto, adequada ao período do pós-guerra, mas geradora de elevados níveis médios de «stocks».

$\mathrm{Na}$ década de 60 , com a introdução do conceito de materiais de consumo dependente e independente surgiram os sistemas MRP («Material Requirements Planning»), muitos dos quais ainda hoje se baseiam na teoria do lote económico de fabrico, no que se refere ao dimensionamento do aprovisionamento interno (fabrico) de materiais dependentes. $O$ conceito de materiais dependentes relaciona o reaprovisionamento interno (fabrico) de produtos intermédios e o reaprovisionamento externo (compra) de matérias-primas e de componentes para integrar no fabrico com as necessidades de produtos acabados. Estes últimos, sendo considerados independentes, tinham o seu reaprovisionamento (fabrico) relacionado com a previsão da procura, as encomendas em carteira e o nível médio de stock a cujas políticas de materiais obrigavam. Outros materiais independentes, como os materiais de manutenção, eram e são reaprovisionados com base na estimativa de consumo e no nível de serviço a manter. Excepções há, por exemplo, de matérias-primas derivadas do petróleo e fibras naturais sazonais e com elevados ciclos de reaprovisionamento que obrigam a compras políticas que se desviam das regras normais, no que se refere às questões quando e quanto aprovisionar.

Este tema é de crucial importância para a gestão fabril. Toda a dinâmica de funcionamento da fábrica desde o fluir dos em-curso-de-fabrico, passando pelas decisões sobre o que fabricar e quando fabricar, as dimensões dos respectivos 
lotes, os níveis de stock a manter e a organização do próprio «layout» é função da filosofia ou sistema de controle de materiais/produção escolhido.

Actualmente, os sistemas de Controle de Materiais poderão considerar-se um componente do Controle da Produção. Enquanto os primeiros se preocupam basicamente com quanto e quando encomendar (fabricar) e com que níveis de stock, os segundos acrescentam as questões relacionadas com a capacidade e a organização fabril.

O Gestor da Produção deverá evitar roturas de stock durante o processo produtivo, mantendo somente os níveis mínimos de inventário e tendo em mente o objectivo zero stocks. Por outro lado, deverá também evitar produzir componentes para armazém, dado que isso ocupará recursos que poderiam estar a fabricar produto necessário para venda. Acresce ainda que um maior nível de em-curso-de-fabrico aumenta o ciclo de fabrico (maiores filas de espera), representa mais capital investido, diminui a flexibilidade do sistema produtivo, gera produto deteriorado e atrapalha o fluir dos materiais e o processo produtivo.

Nas décadas de 70 e 80, com o crescente sucesso da indústria japonesa, surgiu uma tendência para a análise e implantação dos sistemas utilizados pelos Japoneses, nomeadamente o Just-in-Time (JIT). Surgiram ainda outros sistemas alternativos de controle da produção, como é o caso da «Optimised Production Technology» (OPT).

\subsubsection{Controle de Pessoal}

O Gestor da Produção deverá controlar a disponibilidade do pessoal necessário, com a capacidade técnica requerida e na altura certa. Compete-lhe ainda manifestar, atempadamente, as necessidades de mão-de-obra junto do Departamento de Pessoal.

Por outro lado, numa grande parte das empresas, os custos de pessoal representam valores importantes e, como tal, deverão ser controlados.

É também da responsabilidade do Gestor da Produção cooperar com os engenheiros industriais no sentido de se estudarem e implementarem os melhores métodos de trabalho, a mais adequada divisão de tarefas e os respectivos tempos de execução. À «posteriori» a força de trabalho deverá ser formada e treinada para as funções que lhe forem atribuídas.

O Gestor da Produção deverá ainda liderar e dinamizar o treino e a formação necessários a uma mudança do comportamento da força de trabalho. Na fábrica pretendem-se colaboradores responsáveis, motivados, versáteis e a funcionar em autocontrole, isto é sem necessidade do recurso ao policiamento dos inspectores de qualidade e supervisores de produção. Aliás, a redução de indirectos é um dos 
aspectos que tem sido privilegiado na dimiuição de custos e aumento da produtividade.

Salienta-se, ainda, a mudança de atitude das organizações face aos seus trabalhadores. Tem-se vindo a realçar, cada vez mais, a ênfase na parceria e na relação «ganhador-ganhador», em detrimento de outras que muitas vezes acabavam por degenerar em convulsivas e destruidoras lutas de classe, em que todos acabavam por perder. Nesse sentido, tem-se gerado um movimento de dissolução das várias classes de trabalhadores e chefias dentro das organizações. Deixaram de existir os «indians» e os «chiefs» e passou a haver colaboradores.

O Gestor da Produção tem um papel crítico no desenvolvimento de um espírito de grupo e de entreajuda mútua, para o qual poderá ser importante contribuir com um tratamento personalizado em termos, por exemplo, das instalações sanitárias/higiene, áreas de lazer e áreas afectas a grupos de trabalho.

A comunicação e divulgação explícita dos objectivos a atingir e dos valores continuamente actualizados dos índices de «performance» são aspectos essenciais para a motivação dos colaboradores. Muitas empresas usam «placards», publicações periódicas internas e mesmo vídeos com comunicações como meios privilegiados de divulgação da informação.

$\mathrm{O}$ investimento na preparação e mudança de atitude dos colaboradores tem sido reportado como aquele que se traduz num dos maiores retornos em termos tangíveis e intangíveis. Para além disso, é absolutamente essencial ao melhoramento contínuo da «performance» e necessita de relativamente pouco capital quando comparado, por exemplo, com a compra de equipamentos.

\subsubsection{Controle da Manutenção}

O principal objectivo da função manutenção é garantir a máxima disponibilidade e a melhor «performance» dos equipamentos e instalações ao custo mínimo. As actividades de manutenção são importantes pois, por um lado, podem representar custos significativos e, por outro, podem acarretar custos comerciais (intangiveis) importantes.

O Gestor da Produção deverá colaborar com esta função de várias maneiras:

- acordar e cumprir paragens de máquina para revisão em alturas mutuamente favoráveis para o equipamento e para a produção;

- incutir no seu pessoal um espírito de colaboração no que se refere à limpeza, inspecção visual e lubrificação básica dos equipamentos, bem como no seu uso adequado e cuidado;

- garantir a recolha e o registo da informação de retorno da manutenção que seja da sua responsabilidade; 
O Gestor da Produção poderá ainda aceder ao histórico de manutenção dos equipamentos, a fim de obter elementos que lhe permitam optimizar o seu uso.

\subsubsection{Controle de Custos}

A existência de informação adequada, correcta e atempada sobre custos é essencial a uma boa Gestão de Operações. Contudo, apenas poderá ser obtida informação de confiança através de um bom entendimento e comunicação entre os gestores financeiro e da produção. A afectação de custos fixos, tendo em atenção os critérios respectivos, o nível de actividade da fábrica e a «mix» de produtos fabricada são um excelente exemplo da necessidade deste diálogo. Outro, ainda, seria a divisão da fábrica em centros de custos, de tal modo que estes não fossem unidades tão pequenas que gerassem um incomensurável trabalho administrativo, ou tão grandes que não permitissem um rigor aceitável à informação de suporte à tomada de decisão. Inúmeros outros exemplos poderiam ser dados, tais como a elaboração de orçamentos sectoriais, das contas de exploração previsionais, do perfil previsional de «cash-flows», etc.

Conclui-se então que o Gestor da Produção é um elemento fundamental na garantia da fiabilidade dos dados que alimentam os sistemas financeiros. Ele não é somente um contribuinte líquido, pois também deverá utilizar muita dessa informação em proveito próprio. É também da competência do Gestor da Produção colaborar e/ou liderar grupos de trabalho cujo objectivo seja a redução de custos ou o aumento de produtividade. Estes grupos também deverão ser compostos por projectistas, engenheiros industriais e de processo, para além dos representantes dos sectores financeiro e comercial.

\subsection{Estatuto da Função}

O Gestor da Produção deverá aceitar o enriquecimento da sua função que actualmente se perspectiva, em detrimento da passividade da acomodação, pois só assim poderá lidar com a crescente complexidade que o rodeia e alcançar o desempenho que dele se espera. De facto, é necessário que ele esteja consciente do negócio como um todo, sem deixar de estar motivado unicamente para a sua área funcional, que resolva e evite problemas e que considere igualmente relevantes o curto e o longo prazo. 


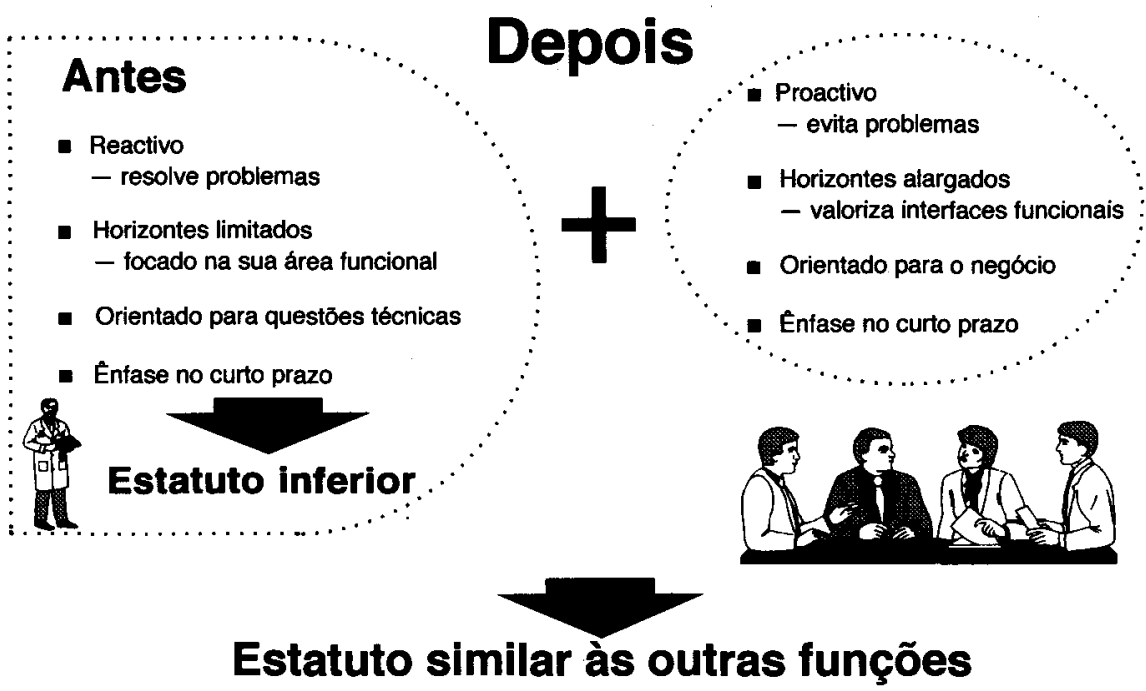

Fig. 2 - A Função Gestão da Produção

Só assim poderá a gestão da produção recuperar o lugar e o destaque que deve ter no contexto da organização, de modo a servi-la o melhor possível.

De seguida irão analisar-se algumas ferramentas de apoio à implementação da mudança sistemática continuamente requerida, no quotidiano do sistema de fabrico.

\section{MELHORAMENTO CONTÍNUO}

\subsection{Introdução dos Conceitos}

A eficaz gestão de operações, por si só, já não é suficiente para assegurar a sobrevivência das organizações industriais. $O$ desempenho dos sistemas de fabrico tem que ser continuamente melhorado, de tal modo que se eliminem todas as formas de desperdício existentes. 


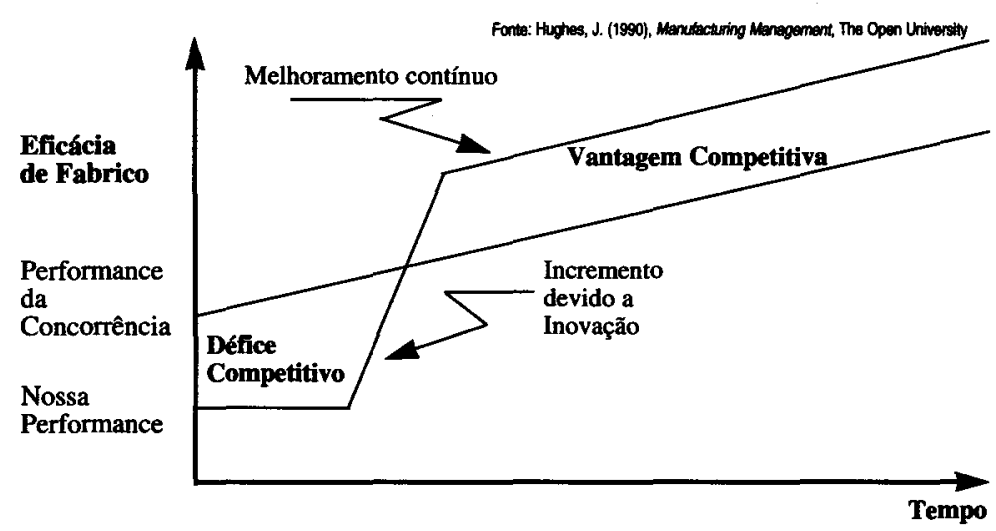

Fig. 3 - Melhoramento Contínuo e Inovação

De acordo com a figura 3, as organizações que se apresentem em desvantagem competitiva face à concorrência deverão empreender acções de inovação que reponham a sua competitividade. Contudo, uma vez na vanguarda, deverá ser activado um processo continuado de melhoramento que garanta a manutenção da liderança.

Inovação e melhoramento contínuo são duas formas de mudança que modificam os parâmetros de operação do sistema e se complementam.

Os processos de inovação não são frequentes, ocorrem com um certo intervalo de tempo, têm um carácter personalizado, imprimem mudanças bruscas e requerem grandes investimentos. Um exemplo típico, embora extremista, é a implantação de uma nova fábrica incorporando os mais recentes avanços tecnológicos, a fim de satisfazer as necessidades de fabrico de um novo produto. Outros melhoramentos mais modestos, tais como a introdução de CAD/CAM, ou de automação flexível, também constituem exemplos de inovação do sistema produtivo.

Por seu lado, o melhoramento contínuo é uma acção que necessita de pequenos investimentos, mas que deverá ser levada a cabo persistentememte no longo prazo através de pequenas mudanças facilmente assimiláveis. Requer ainda a colaboração e o envolvimento de todos os elementos da fábrica num esforço colectivo baseado no espírito de grupo.

Normalmente, os processos de inovação não conseguem atingir em pleno os objectivos que se propõem. Há sempre um ligeiro declínio na «performance», ao longo do tempo, que deve ser colmatado e invertido através do melhoramento contínuo. 


\subsection{Fixação de Objectivos}

Qualquer que seja o negócio, ele deverá satisfazer os interesses de diferentes grupos, tais como, os accionistas, os clientes, os fornecedores, os colaboradores, o estado, etc. Por vezes, muitos dos interesses destes grupos são contraditórios. Há então que estabelecer um rumo para a negócio que é a sua missão e que explicita o que, de facto, é importante para a organização. Por sua vez, a missão servirá de enquadramento aos objectivos estratégicos do negócio, os quais deverão ser transformados em objectivos de mais baixo nível e que façam sentido para cada área funcional.

Os objectivos tradicionais para o sistema de fabrico têm-se limitado ao aumento da produtividade do trabalho e da utilização dos equipamentos, desprezando o sistema produtivo como um todo. Por outro lado, também tradicionalmente o combate ao desperdício tem apenas visado as áreas mais conhecidas, ignorando as menos visíveis. Há pois necessidade de se arranjar um método sistemático de combate ao desperdício e de melhoramento contínuo. Para isso contribui significativamente o estabelecimento dos chamados pseudo-objectivos. Estes, embora não sendo alcançáveis ajudam a focar os programas de melhoramento, constituem um desafio ao modo como o sistema de fabrico é operado e estimulam um esforço de melhoramento constante. Um bom objectivo de melhoramento deve aumentar a vantagem competitiva, apoiar o planeamento estratégico do negócio, aumentar a satisfação dos clientes e focar-se na produtividade ou na qualidade.

Uma alternativa aos pseudo-objectivos são os objectivos estruturados (Fig. 4). Estes níveis mais elevados da organização deverão possuir um âmbito alargado e atingir um vasto horizonte temporal, embora mostrem alguma dificuldade de quantificação. À medida que se desce na hierarquia, tornam-se mais fáceis de quantificar e mais focados no tempo e na área de actuação.

\begin{tabular}{|l|l|}
\hline \multicolumn{1}{|c|}{ Nível } & \multicolumn{1}{c|}{ Objectivo } \\
\hline Negócio & Melhor satisfação do cliente \\
\hline Fábrica & Zero encomendas atrasadas em dois anos \\
\hline Departamento & Menos de 10\% de falhas face ao plano deste ano \\
\hline Secção & $\begin{array}{l}\text { Aumentar disponibilidade dos equipamentos em 15\% neste } \\
\text { semestre }\end{array}$ \\
\hline
\end{tabular}

Fig. 4 - Exemplo de Objectivos Estruturados 


\subsubsection{Pseudo-Objectivos}

Um dos mais conhecidos conjuntos de pseudo-objectivos é o dos sete-zeros, o qual se passa a descrever de seguida:

- zero defeitos - coloca ênfase no fabrico com qualidade, no autocontrole e na eliminação da inspecção, da recuperação do defeituoso e da adição de material extra para desperdício;

- zero «set up» - salienta a flexibilidade do sistema de fabrico e a maximização da disponibilidade dos equipamentos pela eliminação dos tempos de preparação das máquinas;

- zero movimento - refere a eliminação de operações de movimentação de produto, as quais não acrescentam valor;

- zero lote - obriga à redução da dimensão do lote de fabrico para a unidade;

- zero avaria - conduz à anulação do «stock» de salvaguarda de avarias;

- zero variação - ataca as flutuações de velocidade das operações e a criação do «stock» inerente;

- zero prazo - refere a redução dos prazos de entrega, na situação de zero «set up» e zero lote, aos tempos de operação e transporte.

Os pseudo-objectivos focam-se no longo termo e, embora conduzam à maximização do valor acrescentado, não são tão rigorosos e focados quanto os objectivos estruturados.

\subsection{O Método de Melhoramento Contínuo «Just in Time» (JIT)}

Tomado à letra JIT significa a produção e entrega de produtos acabados na altura destes serem vendidos, de produtos intermédios na altura de serem integrados nos produtos acabados, de componentes fabricados na altura de serem integrados nos produtos intermédios e de materiais comprados na altura de serem utilizados no fabrico.

A propósito dos diferentes modos de operar, costuma-se dizer que enquanto os Japoneses produzem pequenas quantidades «just in time», os Ocidentais produzem grandes quantidades «just in case»... 
Ao longo do tempo têm sido atribuídos vários significados ao JIT, nomeadamente:

\section{Sistema de Controle de Materiais}

Muitas vezes o JIT é confundido com «Kanban», o sistema de controle da produção desenvolvido pela Toyota.

Método de Redução de «Stocks»

Por outro lado, também se considera o JIT como um método de produção «sem» stocks, ligado ao conceito de zero stock.

\section{Método de Aumento da Produção}

Uma outra das preocupações do JIT é a remoção dos obstáculos que impedem o fluir dos materiais ao longo do processo de fabrico.

\section{Método de Melhoramento Contínuo}

O JIT é ainda utilizado para se detectarem problemas, através de uma redução sistemática dos inventários e de um combate sem tréguas ao desperdício.

Citam-se, a título de exemplo, alguns dos aspectos que o JIT pretende evitar:

- em-curso-de-fabrico que não está a ser processado é um desperdício de espaço, tempo e dinheiro;

- tempo de preparação dos equipamentos é um desperdício do tempo de produção;

- produto defeituoso e sobras são um desperdício de material;

- a recuperação de produto é um desperdício de tempo, material e capacidade;

- os recursos a trabalharem para «stock» são um desperdício de capacidade.

Conclui-se assim a análise do segundo aspecto mais importante da função do Gestor da Produção - o melhoramento contínuo. Este, a par com a garantia de conformidade no fabrico/e a gestão de operações constituem as suas responsabilidades primárias. Outras competências secundárias poderão ser referidas, como por exemplo a contribuição para o processo de inovação, em termos de desenvolvimento do produto e do sistema de fabrico.

\section{CONCLUSÕES}

Pretendeu-se com este artigo invocar alguns dos mais críticos desafios que se colocam a uma gestão actualizada dos sistemas produtivos. 
Tentou-se ainda facultar uma perspectiva integrada do tipo causa-efeito da função gestão da produção, nas organizações industriais e, destas, no seu contexto competitivo envolvente. Concluiu-se desta análise existir uma necessidade premente de mudança das organizações que prezem a sua sobrevivência. Este requisito de busca continuada do óptimo e da excelência foi suportado por métodos que permitem um apoio sistemático à perseguição dos objectivos ideais da organização.

Como benefício principal, espera-se que tenha sido alcançada uma visão abrangente da problemática em estudo. Como consequência desta abrangência, a dificuldade mais importante que se encontrou, ao longo da redacção do artigo, reportou-se à vastidão de muitos dos temas focados. Como facilmente se depreende, os assuntos tratados não se esgotam nos comentários tecidos.

\section{BIBLIOGRAFIA}

Ackoff, R. L., 1974, Redesigning the Future, New York, Wiley.

Amado Mendes, J., 1922, «Cultura de Empresa: Uma Nova Dinâmica Organizacional», Gestão e Desenvolvimento, N. ${ }^{\circ} 1, \mathrm{UCP} / \mathrm{CRV} / \mathrm{IUDPS}$.

Dooner, M. \& Seville, T., 1990, Managing Operations. The Open University, Milton Keynes.

Galgut, P., 1990, Production Planning and Control handouts, College of Manufacturing, Cranfield Institute of Technology, 1990.

Hammer, M. \& Champy J., 1993, Reengineering the Corporation, London, Nicholas Brealey, Pub.

Hill, T., 1989, Manufacturing Strategy, London, Macmillan Education.

Hughes, J., 1990, A Modern Approach to Manufacturing Management, The Open University, Milton Keynes.

Hughes, J., 1990, Integration and Innovation, The Open University, Milton Keynes.

Hughes, J. \& Stone, S., 1990, Continuous Performance Improvement, The Open University, Milton Keynes.

Mintzberg, H, 1973, The Nature of Managerial Work, New York, Harper \& Row.

Orlicky, J., 1975, Material Requirements Planning, New York, McGraw-Hill.

Schonberger, R., 1982, Japanese Manufacturing Techniques, New York, The Free Press.

Stewart, R., 1983, Choices for Managers, London, McGraw-Hill.

Wild, 1986, «Operations Management in the 1990s», International Journal of Operations and Production Research, vol. 6, N. ${ }^{\circ} 4$. 